\title{
Association between connexin 40 and potassium voltage-gated channel subfamily A member 5 expression in the atrial myocytes of patients with atrial fibrillation
}

\author{
FEI ZHANG ${ }^{1}$, YUHAO BIAN ${ }^{1,2}$, LEI HUANG ${ }^{1}$ and WENBIN FAN ${ }^{1}$ \\ ${ }^{1}$ Department of Cardiothoracic Surgery, Nanshan People's Hospital, Shenzhen, Guangdong 518052; \\ ${ }^{2}$ Graduate School, Guangzhou Medical University, Guangzhou, Guangdong 510182, P.R. China
}

Received May 9, 2016; Accepted March 17, 2017

DOI: $10.3892 / e t m .2017 .5129$

\begin{abstract}
Structural and electrical remodeling within the atrium mediate the pathogenesis of atrial fibrillation (AF). Two key genes that sever a role in this remodeling are connexin 40 (Cx40) and potassium voltage-gated channel subfamily A member 5 (KCNA5), respectively. Electrical remodeling is considered to induce structural remodeling during AF. In the present study, the left atrial appendage section and atrial myocytes of patients with AF were evaluated. It was observed that $\mathrm{Cx} 40$ and KCNA5 mRNA $(\mathrm{P}<0.05)$ and protein $(\mathrm{P}<0.01)$ expression was significantly downregulated in AF compared with rheumatic heart disease. In addition, a positive correlation between the mRNA expression Cx40 and KCNA5 was observed in the atrial myocytes of patients with $\mathrm{AF}(\mathrm{P}<0.05$; $\mathrm{r}=0.42$ ). The association between $\mathrm{Cx} 40$ and KCNA5 expression was subsequently investigated in primary cultured atrial myocytes using siRNA transfection. In atrial myocytes, downregulation of $\mathrm{Cx} 40$ inhibited the expression of KCNA5. Similarly, silencing of KCNA5 suppressed the expression of $\mathrm{Cx} 40$. These results indicate that synergistic regulation may occur between $\mathrm{Cx} 40$ and KCNA5 expression. Furthermore, the combined effects of electrical and structural remodeling in the atrial myocytes of patients with AF may contribute to the pathogenesis of AF.
\end{abstract}

\section{Introduction}

Atrial fibrillation (AF) is the most prevalent form of sustained arrhythmia (1). Treatment strategies for AF (120-180 times/min) aim to regulate the heart rate to a

Correspondence to: Professor Fei Zhang, Department of Cardiothoracic Surgery, Nanshan People's Hospital, 89 Taoyuan Road, Shenzhen, Guangdong 518052, P.R. China

E-mail: fei.zhang263@163.com

Key words: connexin 40, potassium voltage-gated channel subfamily A member 5, atrial myocytes, atrial fibrillation, electrical remodeling, structural remodeling near normal range (60-100 times/min), typically with drug therapy (2). Abnormal heart rhythm may lead to heart palpitations, fainting, shortness of breath, chest pain and fatality. Risk factors for AF include heart failure, dementia and stroke, and the incidence of AF increases with age (2). AF is an important focus of research into heart disease. In China, the prevalence of $\mathrm{AF}$ is 0.77 , and $7.5 \%$ of all patients with AF are $>80$ years (3). The pathogenesis of AF is not yet fully understood, and the efficacy of current treatment strategies is poor.

Cardiac electrophysiological processes are essential for heart function, and are regulated by changes in the expression and activity of ion channel membrane proteins and connexin $(\mathrm{Cx})$ proteins $(4,5)$. Electrical and structural remodeling are among the primary characteristics of cellular electrophysiology in AF (6). The majority of heart disease is caused by abnormal expression of ion channel proteins and Cx proteins (7-9). Previous studies have investigated the underlying molecular mechanisms that affect the development of AF (10-13), revealing that the occurrence and maintenance of chronic AF is regulated by multiple genes and proteins, including L-type calcium channel and sarcoplasmic reticulum $\mathrm{Ca}^{2+}$-ATPase (10). However, the association between these multiple genes and proteins remains unclear.

Recent studies have indicated that potassium voltage-gated channel subfamily A member 5 (KCNA5) and $\mathrm{Cx}$ proteins serve a role in the pathogenesis of $\mathrm{AF}(11,14,15)$. In turn, a number of drugs that target KCNA5 and Cx40 have been identified (16-20). For instance, Vernakalant (RSD1235; Cardiome Pharma Corp., Vancouver, BC, Canada) is a drug that exhibits high affinity for KCNA5 and has arrhythmia-specific effects (21). Furthermore, intravenous administration of Vernakalant in phase II and III clinical trials caused cardioversion effects (22). However, the electrophysiological properties of atrial ion channels, and the regulation of KCNA5 and Cx40, during AF are not well understood.

KCNA5 and Cx40 may exert combined effects on electrophysiological function during AF. Therefore, the present study used RNA interference to investigate the effects of KCNA5 and Cx40 on cardiomyocyte function during AF. The results of the present study may improve understanding of the pathogenesis of AF, and aid in the prevention and treatment of AF. 


\section{Materials and methods}

Patients. A total of 60 patients were included in the present study. Of these patients, 30 presented with persistent AF, while 30 presented with rheumatic heart disease and were used as a control group. The patients were enrolled between September 2014 and September 2015 in the Department of Cardiothoracic Surgery, Nanshan People's Hospital of Shenzhen (Shenzhen, Guangdong). The clinical characteristics of all patients are presented in Table I. Patients with persistent AF and patients with rheumatic heart disease were matched based on typical clinical symptoms. In patients with $\mathrm{AF}$, the ventricular rates were fast (up to $120-180$ times/min) and irregular. The rhythm was irregular with unequal heart sounds and short pulses (the pulse rate was lower than the heart rate). In patients with rheumatic heart disease, valve lesions observed included mitral stenosis or mitral regurgitation. AF was diagnosed by evaluating patient medical records and the results of a 12-lead electrocardiogram. In atrial fibrillation, the P-wave disappeared and was replaced by the atrial fibrillation wave. Furthermore, the R-R interval was irregular and the ventricular rate was irregular (120-180 times/min). Additionally, the QRS complex was deformed and rheumatic heart disease was diagnosed using Doppler echocardiography. In rheumatic heart disease, mitral valve leaflets were thickened and were observed on ultrasound as a hyperechoic area. Furthermore, the activity range was decreased and the diastolic anterior lobe was bulging in a balloon-shaped. The tip of the front and rear leaf distance was notably shortened. Additionally, the distance between the front and back of the valve tip was shortened and the opening area was reduced. Atrial muscle tissues from the left atrial appendage section were collected during heart valve replacement surgery. Written informed consent was obtained from all patients, and the experimental procedures were approved by the Ethics Committee of the Nanshan People's Hospital of Shenzhen (Shenzhen, China) and performed according to their guidelines.

Cell culture. Atrial myocytes from the left side of the heart were obtained from 3 enrolled patients. Briefly, a $1 \mathrm{~mm}^{3}$ atrial muscle segment was washed in PBS (Sangon Biotech Co., Ltd., Shanghai, China). The $1 \mathrm{~mm}^{3}$ atrial muscle segments were placed in cell culture flasks (Thermo Fisher Scientific, Inc., Waltham, MA, USA) and incubated at $37^{\circ} \mathrm{C}$ in an atmosphere containing $5 \% \mathrm{CO}_{2}$. Once the cells reached up to $80 \%$ confluence, the cells adhered to the flask were washed with PBS and $0.25 \%$ Trypsin (Sangon Biotech Co., Ltd., Shanghai, China) for $5 \mathrm{~min}$. The washed cells were centrifuged for $3 \mathrm{~min}$ at room temperature $500 \mathrm{xg} / \mathrm{min}$ to obtain the passage cells. Cells were adhered to cell culture flasks. Cells were incubated at $37^{\circ} \mathrm{C}$ with $5 \% \mathrm{CO}_{2}$ for $90 \mathrm{~min}$, prior to the addition of Dulbecco's modified Eagle's medium (DMEM) supplemented with 15\% fetal bovine serum (Invitrogen; Thermo Fisher Scientific, Inc., Waltham, MA, USA). The medium was replaced every 3 days. Upon reaching $\sim 80 \%$ confluence, cells were passaged into new flasks. The following experiments were conducted on the third generation of passaged cells.

RNA interference. Cells were plated into 96-well plates at a concentration of $1.0 \times 10^{5}$ cells $/ \mathrm{ml}$ in DMEM and cultured for $24 \mathrm{~h}$ at $37^{\circ} \mathrm{C}$ with $5 \% \mathrm{CO}_{2}$. Cells were subsequently transfected with Cx40-small interfering RNA (siRNA) (cat. no. HSS104129) and KCNA5-siRNA (cat. no. HSS105670) (both from Invitrogen; Thermo Fisher Scientific, Inc.). Briefly, cells were treated with 10 pmol Cx40-siRNA or KCNA5-siRNA and $0.5 \mu 1$ Lipofectamine ${ }^{\circledR} 2000$ (Invitrogen; Thermo Fisher Scientific, Inc.) for $24 \mathrm{~h}$ at $37^{\circ} \mathrm{C}$. Untransfected cells were used as the control. Following treatment, the transfection solution was replenished with fresh DMEM medium. Total RNA was extracted from cells and levels of target gene inhibition were determined.

Reverse transcription-quantitative polymerase chain reaction (RT-qPCR) analysis. Total RNA was extracted using TRIzol reagent (Invitrogen; Thermo Fisher Scientific, Inc.) according to the manufacturer's instructions, and the quantity of extracted RNA was measured using an ultraviolet spectrophotometer (NanoDrop; Thermo Fisher Scientific, Inc.). The A260/280 was used to analyze the RNA purity (when A260/280=1.8-2.1, the sample was used). The RNA quantification was based on Beer-Lambert law: $\mathrm{A}=\varepsilon \mathrm{cl}$ ( $\mathrm{A}=$ absorbance, $\varepsilon=$ extinction coefficient, $\mathrm{c}=$ concentration and $\mathrm{l}=$ path length) according to the instruction of manufacturers. Reverse transcription was performed using a PrimeScript RT reagent kit with gDNA Eraser (Takara Bio, Inc., Otsu, Japan) with $1 \mu \mathrm{g}$ total RNA according to the manufacturer's instructions. qPCR was performed using a Takara SYBR Green PCR kit (DRR820A; Takara Bio, Inc.) with an ABI 7300 Real-Time PCR system (Applied Biosystems; Thermo Fisher Scientific, Inc.). The qPCR thermocycling conditions were as follows: $95^{\circ} \mathrm{C}$ for $15 \mathrm{~min} ; 40$ cycles at $95^{\circ} \mathrm{C}$ for $10 \mathrm{sec}, 60^{\circ} \mathrm{C}$ for $20 \mathrm{sec}$ and $72^{\circ} \mathrm{C}$ for $15 \mathrm{sec}$. Primers were designed using Primer Express software (version 2.0.0; Applied Biosystems; Thermo Fisher Scientific, Inc.). The primers used were as follows: $\mathrm{Cx} 40$ forward, $5^{\prime}-\mathrm{CCG}$ GCCCACAGAGAAGAATGT-3' and reverse, 5'-TCTGACCTT GCCTTGCTGCTG-3'; KCNA5 forward, 5'-CAGAGTCTC CAAGCAGAAGG-3' and reverse, 5'-CCAGGTGTGGCTTAT CTTCG-3'; and GAPDH forward, 5'-ACTCTGGCAAAGTGG ATATTGTCG-3' and reverse, 5'-CAGCATCACCCCATTTGA TG-3'. Levels of gene expression relative to that of GAPDH were calculated using the $2^{-\Delta \Delta C q}$ method (23). Four replicates were performed for each $\mathrm{qPCR}$ reaction.

Western blot analysis. Following transfection, proteins were extracted from cells using RIPA lysis buffer (Beyotime Institute of Biotechnology, Shanghai, China) and separated using $10 \%$ SDS-PAGE. Proteins were then transferred onto polyvinylidene difluoride membranes (Merck KGaA, Darmstadt, Germany). The blocking of proteins was performed at room temperature in 5\% non-fat dry milk for $1 \mathrm{~h}$. The following polyclonal rabbit primary antibodies were used: $\mathrm{Cx} 40$ (1:500, cat. no. ab38580), KCNA5 (1:500, cat. no. ab181798) and GAPDH (1:1,000, cat. no. ab9485). Following incubation with primary antibodies for $18 \mathrm{~h}$ at $4^{\circ} \mathrm{C}$, the membrane was rinsed 3 times with wash buffer 1X phosphate-buffered saline with Tween-20 (PBST) wash buffer (Beyotime Institute of Biotechnology, Shanghai, China). The secondary antibody was goat polyclonal anti-rabbit immunoglobulin $\mathrm{G}(1: 2,000$, cat. no. ab150077), which was incubated with membrane at room temperature for $2 \mathrm{~h}$ following washing with 1X PBST wash buffer 3 times. All antibodies were purchased from Abcam (Cambridge, UK). 
Protein expression was analyzed using ECL Western Blotting substrate (Pierce; Thermo Fisher Scientific, Inc.). Western blot images were captured using a ChemiDoc XRS system (Bio-Rad Laboratories, Inc., Hercules, CA, USA). Protein levels were determined relative to GAPDH using Image-Pro Plus software (version 6.0; Media Cybernetics, Inc., Rockville, MD, USA).

Statistical analysis. SPSS software (version 17.0; SPSS, Inc., Chicago, IL, USA) was used for all statistical analyses. Data are expressed as the mean \pm standard deviation. An independent samples t-test was used to compare levels of gene and protein expression between groups. Pearson's correlation coefficient was used to measure the association between Cx40 and KCNA5 expression in atrial myocytes. All analyses were conducted as two-tailed tests. $\mathrm{P}<0.05$ was considered to indicate a statistically significant difference. Linear regression analysis was plotted using GraphPad Prism 5 (GraphPad Software, Inc., La Jolla, CA, USA) to indicate the correlation between $\mathrm{Cx} 40$ and KCNA5 expression.

\section{Results}

Expression of CX40 and KCNA5 is decreased in patients with $A F$. To evaluate the expression of $\mathrm{Cx} 40$ and KCNA5 in patients with AF, RT-qPCR and western blotting were used to measure the levels of Cx40 and KCNA5 mRNA and protein, respectively, in the atrial myocytes of patients with AF and rheumatic heart disease. It was observed that levels of Cx40 and KCNA5 mRNA $(\mathrm{P}<0.01$; Fig. $1 \mathrm{~A})$ and protein $(\mathrm{P}<0.05$; Fig. 1B) were significantly reduced in the atrial myocytes of patients with AF patients compared with the control patients with rheumatic heart disease.

CX40 and KCNA5 mRNA expression is positively correlated in patients with $A F$. To determine whether mRNA levels of Cx40 and KCNA5 were associated in patients with AF, the Pearson's correlation coefficient test was performed on the expression data from 30 patients with AF. It was observed that levels of Cx40 and KCNA5 mRNA were positively correlated $(\mathrm{P}<0.05$, $\mathrm{r}=0.42$; Fig. 2), indicating a potential association between the expression of Cx40 and KCNA5 in patients with AF. In addition, using linear regression analysis, the line of best fit was determined to be $y=0.237 x+5.003$, indicating a positive correlation between $\mathrm{Cx} 40$ and KCNA5 expression.

Inhibition of CX40 expression reduces KCNA5 expression in atrial myocytes. To evaluate the association between $\mathrm{Cx} 40$ and KCNA5 expression in patients with AF, Cx40-siRNA was transfected into atrial myocytes collected from the patients. Knockdown of Cx40 was subsequently validated by RT-qPCR and western blot analysis. The results indicated that $\mathrm{Cx} 40$ mRNA (1.31 \pm 0.53 vs. $7.21 \pm 1.33, \mathrm{P}<0.05$; Fig. $3 \mathrm{~A})$ and protein $(1.10 \pm 0.56$ vs. $4.46 \pm 1.21, \mathrm{P}<0.05$; Fig. $3 \mathrm{~B}$ and $\mathrm{C})$ expression was significantly decreased by $\mathrm{Cx} 40$-siRNA transfection compared with the untransfected control cells.

In the atrial myocytes transfected with Cx40-siRNA, mRNA (1.54 \pm 0.52 vs. $10.44 \pm 2.34, \mathrm{P}<0.05$; Fig. $4 \mathrm{~A})$ and protein $(1.10 \pm 0.08$ vs. $3.21 \pm 0.43, \mathrm{P}<0.05$; Fig. $4 \mathrm{~B}$ and $\mathrm{C})$ levels of KCNA5 were significantly decreased compared with the control cells.
Table I. Clinical characteristics of the patients included in the present study.

Type of disease

(mean \pm standard deviation)

\begin{tabular}{lcc}
\cline { 2 - 3 } Characteristics & RHD $(\mathrm{n}=30)$ & AF $(\mathrm{n}=30)$ \\
\hline Sex (n) & & \\
Male & 13 & 15 \\
Female & 17 & 15 \\
Age (years) & $47.33 \pm 6.78$ & $52.68 \pm 10.65$ \\
LA (mm) & $37.52 \pm 4.71$ & $34.98 \pm 5.78$ \\
RA (mm) & $33.91 \pm 3.99$ & $35.16 \pm 4.88$ \\
EF $(\%)$ & $60.62 \pm 7.54$ & $43.06 \pm 10.62^{\mathrm{a}}$
\end{tabular}

${ }^{a} \mathrm{P}<0.05$ vs. the RHD control group. RHD, rheumatic heart disease; $\mathrm{AF}$, atrial fibrillation; LA, inner diameter of the left atrium; RA, inner diameter of the right atrium; EF, left ventricular ejection fraction.

Inhibition of KCNA5 expression reduces $C x 40$ expression in atrial myocytes. The effects of KCNA5 inhibition on the expression of $\mathrm{Cx} 40$ were assessed by transfecting KCNA5-siRNA into atrial myocytes. Following KCNA5-siRNA transfection, knockdown of KCNA5 was validated by RT-qPCR and western blot analysis. It was observed that KCNA5-siRNA transfection significantly reduced the expression of KCNA5 mRNA (1.69 \pm 0.87 vs. $18.90 \pm 4.56, \mathrm{P}<0.05$; Fig. $5 \mathrm{~A})$ and protein $(1.58 \pm 0.50$ vs. $6.98 \pm 1.82, \mathrm{P}<0.05$; Fig. $5 \mathrm{~B}$ and $\mathrm{C})$ compared with the control group.

In the atrial myocytes transfected with KCNA5-siRNA, levels of $\mathrm{Cx} 40$ mRNA $(\mathrm{P}<0.05$; Fig. $6 \mathrm{~A})$ and protein $(\mathrm{P}<0.05$; Fig. $6 \mathrm{~B}$ and $\mathrm{C}$ ) were significantly decreased compared with the control cells.

\section{Discussion}

$\mathrm{AF}$ is the most prevalent type of arrhythmia, although it's the molecular mechanisms underlying its pathogenesis are not well understood. Compared with rheumatic heart disease, AF presents with more severe clinical symptoms, including a markedly lower left ventricular ejection fraction (24). In the present study, levels of $\mathrm{Cx} 40$ and KCNA5 expression in atrial myocytes from patients with AF were evaluated. It was observed that Cx40 and KCNA5 were significantly downregulated in the atrial myocytes of patients with AF when compared with those in patients with rheumatic heart disease. Similarly, previous results have indicated that Cx40 expression is reduced during $\mathrm{AF}$, and that the distribution of $\mathrm{Cx} 40$ may be altered in AF (25). These data suggest that $\mathrm{Cx} 40$ expression is altered in AF. Furthermore, reduced expression of KCNA5 has been observed in AF (26). Cx40 and KCNA4 are considered to regulate structural and electrical remodeling during $\operatorname{AF}(11,12)$; however, the association between the expression of Cx40 and KCNA4 is remains unclear.

AF may lead to long-term structural remodeling within atrial myocytes and the myocardial interstitium (27). Structural remodeling typically occurs in the left atrium (28), and is 

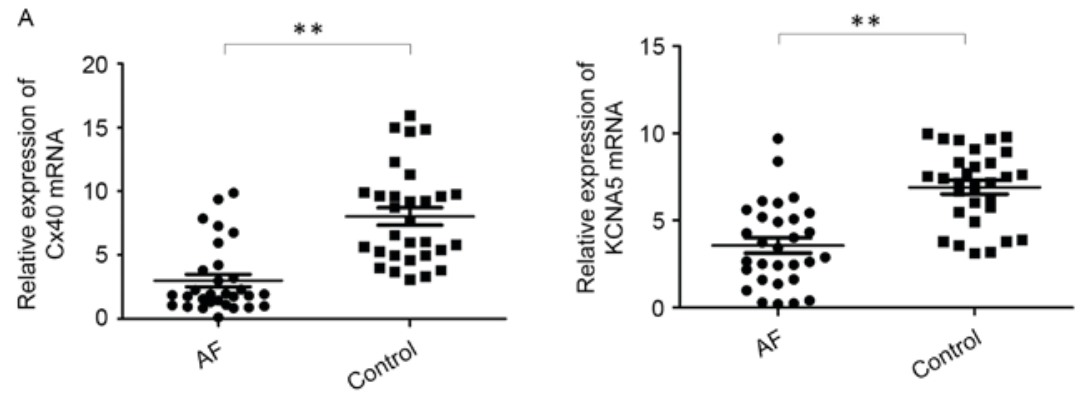

B

C
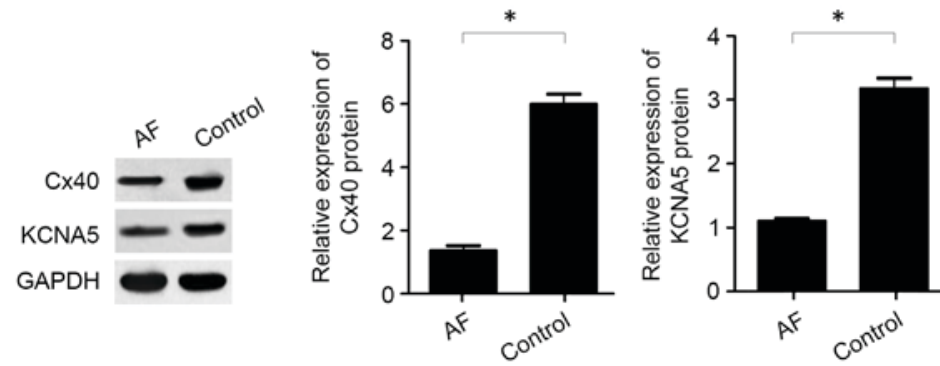

Figure 1. Expression of $\mathrm{Cx} 40$ and KCNA5 in AF and rheumatic heart disease. (A) mRNA expression of Cx40 and KCNA5 in atrial myocytes, measured by RT-qPCR analysis. (B) Protein expression of Cx40 and KCNA5, measured by western blot analysis. (C) Levels of Cx40 and KCNA5 protein expression relative to GAPDH expression. ${ }^{*} \mathrm{P}<0.05,{ }^{* *} \mathrm{P}<0.01$. AF, atrial fibrillation; Cx40, connexin 40; KCNA5, potassium voltage-gated channel subfamily A member 5; RT-qPCR, reverse transcription-quantitative polymerase chain reaction.

considered to worsen the pathological changes, including disregulated cellular energy balance and an increased inflammatory response (28). Within the myocardium, gap junctions provide cytoplasmic continuity between myocytes (29). A number of transmembrane proteins within gap junctions belong to the Cx protein family, including Cx40, 43 and 45 (30). In $\mathrm{AF}$, structural remodeling associated with $\mathrm{Cx}$ proteins may alter the composition of gap junctions and distribution of connective fibers (31). Notably, aberrant distribution of Cx40 protein has been documented in $\mathrm{AF}$, and mutant $\mathrm{Cx} 40$ protein has been associated with a higher risk of AF (12).

Electrical remodeling of the atrial myocardium leads to decrease in contractility and increases the risk of stroke (32). Rapid atrial contraction may also result in heart failure. Therefore, reversal of the electrical remodeling that occurs may be a novel treatment strategy for AF. Previous studies have documented that AF may be induced by a shortening of action potential duration $(1,2,6)$. Ion channels serve a key role in changes to membrane potential. KCNA5 is a member of the potassium voltage-gated channel family, which is considered to be the most complex class of voltage-gated ion channel (33). KCNA5 encodes a potassium channel that serves a role in vascular function by regulating smooth muscle contraction, neurotransmitter release and epithelial electrolyte transport (11).

In the present study, $\mathrm{Cx} 40$ and KCNA5 were downregulated in the atrial myocytes of patients with AF. These two genes have been associated with the worsening of symptoms and an increased risk of morbidity in patients with $\operatorname{AF}(11,12)$. The present study assessed the potential association between Cx40 and KCNA5 expression at the transcriptional and translational levels. In patients with AF, it was observed that mRNA and protein levels of $\mathrm{Cx} 40$ and KCNA5 were

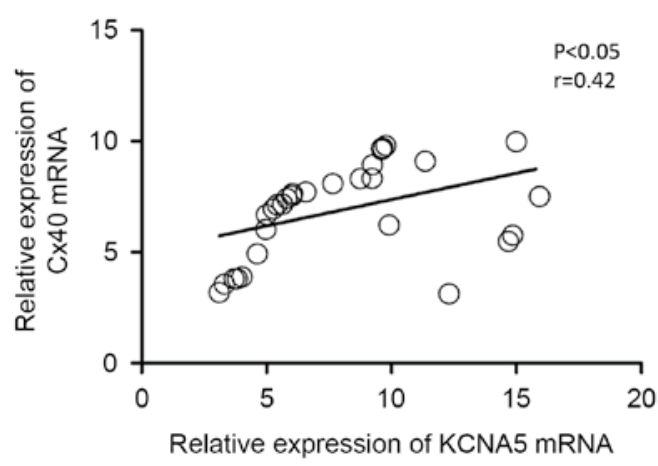

Figure 2. Pearson's correlation coefficient test of Cx40 and KCNA5 mRNA expression in the atrial myocytes of patients with atrial fibrillation. Cx40, connexin 40; KCNA5, potassium voltage-gated channel subfamily A member 5 .

significantly positively correlated, indicating that there is an association between $\mathrm{Cx} 40$ and KCNA5 expression. Previous studies have indicated that structural and electrical remodeling results in a poor prognosis for patients with AF $(34,35)$. However, the link between these changes is not well understood.

The present study was the first, to the best of our knowledge, to assess the association between structural and electrical remodeling in $\mathrm{AF}$, and observed that structural and electrical changes to the atrial myocardium were correlated, which was indicated by the correlation between $\mathrm{Cx} 40$ and KCNA5 in the present study. During the initial stage AF, electrophysiological changes in the atrial myocytes occur, typically within the first few h of sustained atrial tachycardia $(36,37)$. Structural remodeling then occurs at a slower rate following the initial electrophysiological changes (6). Subsequently, structural remodeling alters the architecture of the atrial myocardium. 

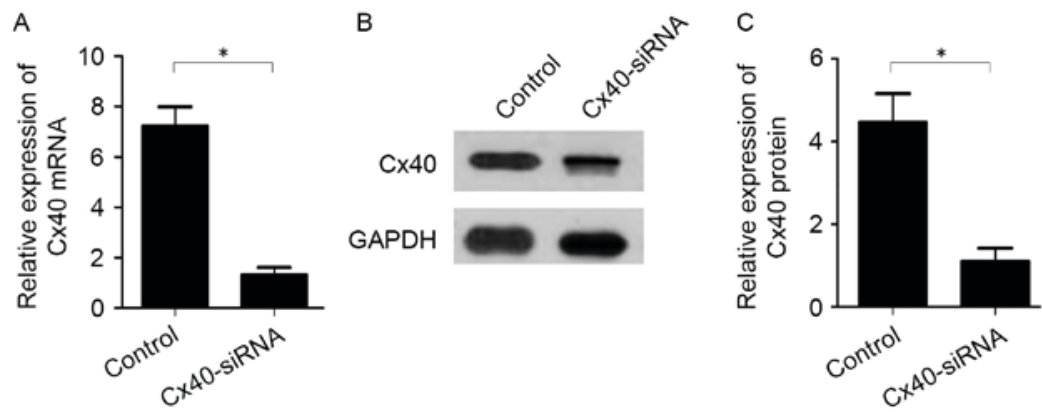

Figure 3. Expression of $\mathrm{Cx} 40$ following $\mathrm{Cx} 40$-siRNA transfection in atrial myocytes. (A) mRNA expression of Cx40 measured by RT-qPCR analysis. (B) Protein expression of $\mathrm{Cx} 40$ measured by western blot analysis. (C) Level of $\mathrm{Cx} 40$ protein expression relative to GAPDH expression. " $\mathrm{P}<0.05$. Cx40, connexin 40 ; siRNA, small interfering RNA; RT-qPCR, reverse transcription-quantitative polymerase chain reaction.
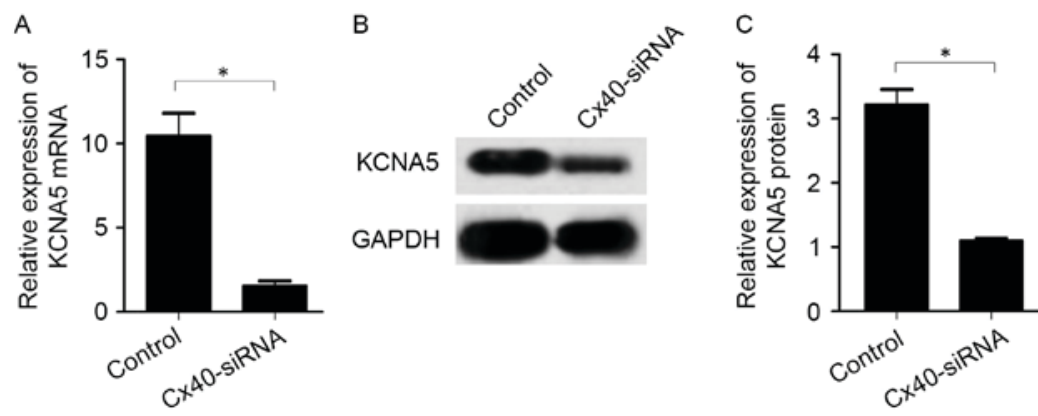

Figure 4. Expression of KCNA5 following Cx40-siRNA transfection in atrial myocytes. (A) mRNA expression of KCNA5 measured by RT-qPCR analysis. (B) Protein expression of KCNA5 measured by western blot analysis. (C) Level of KCNA5 protein expression relative to GAPDH expression. "P $<0.05$. Cx40, connexin 40; KCNA5, potassium voltage-gated channel subfamily A member 5; siRNA, small interfering RNA; RT-qPCR, reverse transcription-quantitative polymerase chain reaction.
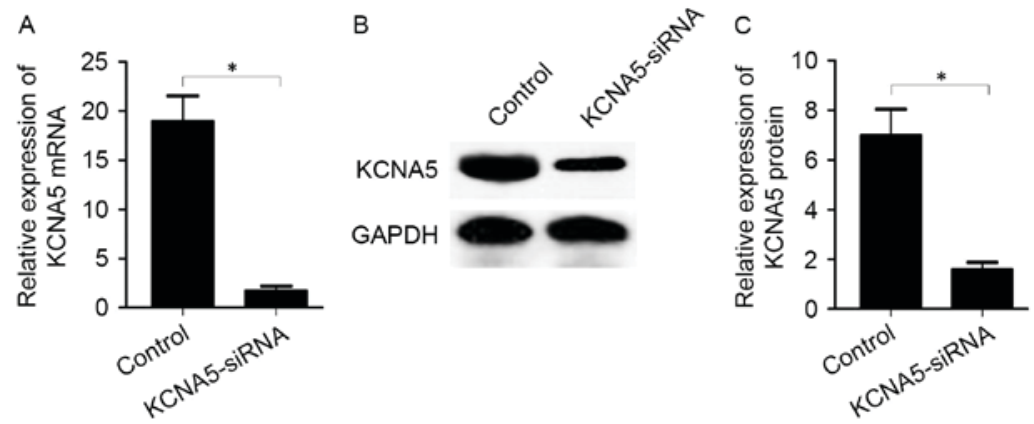

Figure 5. Expression of KCNA5 following KCNA5-siRNA transfection in atrial myocytes. (A) mRNA expression of KCNA5 measured by RT-qPCR analysis. (B) Protein expression of KCNA5 measured by western blot analysis. (C) Level of KCNA5 protein expression relative to GAPDH expression. "P<0.05. KCNA5, potassium voltage-gated channel subfamily A member 5; siRNA, small interfering RNA; RT-qPCR, reverse transcription-quantitative polymerase chain reaction.
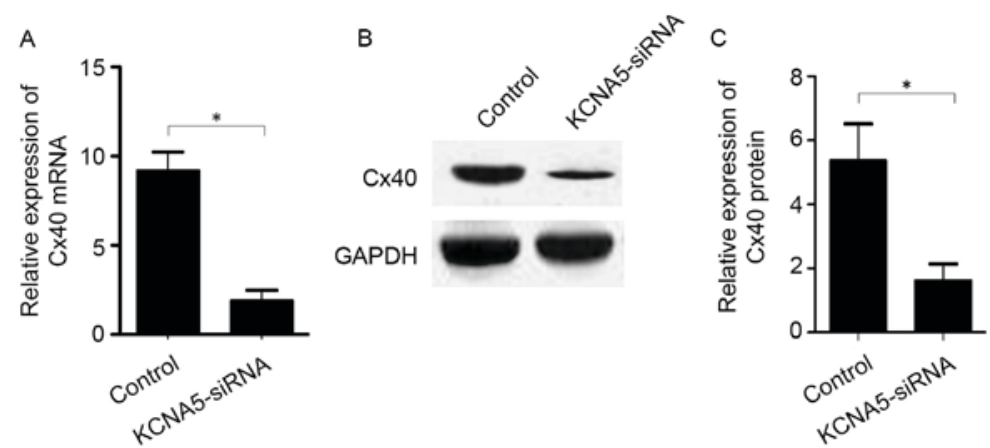

Figure 6. Expression of $\mathrm{Cx} 40$ following KCNA5-siRNA transfection in atrial myocytes. (A) mRNA expression of Cx40 measured by RT-qPCR analysis. (B) Protein expression of $\mathrm{Cx} 40$ measured by western blot analysis. (C) Level of $\mathrm{Cx} 40$ protein expression relative to GAPDH expression." $\mathrm{P}<0.05$. Cx40, connexin 40 ; KCNA5, potassium voltage-gated channel subfamily A member 5; siRNA, small interfering RNA; RT-qPCR, reverse transcription-quantitative polymerase chain reaction. 
In the present study, downregulation of KCNA5 inhibited the expression of $\mathrm{Cx} 40$, suggesting that key molecules associated with electrophysiological changes may regulate Cx40 expression. Therefore, electrophysiological changes may induce structural remodeling by altering the expression of $\mathrm{Cx} 40$. Furthermore, it was observed that downregulation of $\mathrm{Cx} 40$ reduced the expression of KCNA5, indicating that structural remodeling may also affect electrical remodeling. These data indicate that synergistic regulation may occur between $\mathrm{Cx} 40$ and KCNA5 expression to form a network of electrical and structural remodeling during AF.

In conclusion, the present study identified that there was reduced expression of $\mathrm{Cx} 40$ and KCNA5 in the atrial myocytes of patients with AF. A positive correlation was also observed between the expression of $\mathrm{Cx} 40$ and KCNA5 at the mRNA level and protein levels, and using siRNA transfection a potential regulatory relationship between $\mathrm{Cx} 40$ and KCNA5 was identified. These data suggest that there is an association between Cx40 and KCNA5 expression in the atrial myocytes of patients with AF. The present results may be useful in improving the understanding and treatment of AF. Future studies are required to fully elucidate the use of $\mathrm{Cx} 40$ and KCNA5 connection in treating AF.

\section{Acknowledgements}

The present study was supported by the Shenzhen Scientific Research Program of the People's Republic of China (grant nos. JCYJ20130322154529556 and 2012003).

\section{References}

1. Frustaci A, Chimenti C, Bellocci F, Morgante E, Russo MA and Maseri A: Histological substrate of atrial biopsies in patients with lone atrial fibrillation. Circulation 96: 1180-1184, 1997.

2. Le Heuzey JY, Breithardt G, Camm J, Crijns H, Dorian P, Kowey PR, Merioua I, Prystowsky EN, Schwartz PJ, Torp-Pedersen C and Weintraub W: The RecordAF study: Design, baseline data, and profile of patients according to chosen treatment strategy for atrial fibrillation. Am J Cardiol 105: 687-693, 2010.

3. Zhou Z and Hu D: An epidemiological study on the prevalence of atrial fibrillation in the Chinese population of mainland China. J Epidemiol 18: 209-216, 2008.

4. Verheijck EE, van Kempen MJ, Veereschild M, Lurvink J, Jongsma HJ and Bouman LN: Electrophysiological features of the mouse sinoatrial node in relation to connexin distribution. Cardiovasc Res 52: 40-50, 2001.

5. Jalife J, Morley GE and Vaidya D: Connexins and impulse propagation in the mouse heart. J Cardiovasc Electrophysiol 10 1649-1663, 1999.

6. Allessie M, Ausma J and Schotten U: Electrical, contractile and structural remodeling during atrial fibrillation. Cardiovasc Res 54: 230-246, 2002.

7. Kumar NM and Gilula NB: The gap junction communication channel. Cell 84: 381-388, 1996.

8. Goodenough DA and Paul DL: Beyond the gap: Functions of unpaired connexon channels. Nat Rev Mol Cell Biol 4: 285-294, 2003.

9. Schram G, Pourrier M, Melnyk P and Nattel S: Differential distribution of cardiac ion channel expression as a basis for regional specialization in electrical function. Circ Res 90: 939-950, 2002.

10. Brundel BJ, Van Gelder IC, Henning RH, Tuinenburg AE, Deelman LE, Tieleman RG, Grandjean JG, van Gilst WH and Crijns HJ: Gene expression of proteins influencing the calcium homeostasis in patients with persistent and paroxysmal atrial fibrillation. Cardiovasc Res 42: 443-454, 1999.
11. Olson TM, Alekseev AE, Liu XK, Park S, Zingman LV, Bienengraeber M, Sattiraju S, Ballew JD, Jahangir A and Terzic A: Kv1.5 channelopathy due to KCNA5 loss-of-function mutation causes human atrial fibrillation. Hum Mol Genet 15: 2185-2191, 2006

12. Gollob MH, Jones DL, Krahn AD, Danis L, Gong XQ, Shao Q, Liu X, Veinot JP, Tang AS, Stewart AF, et al: Somatic mutations in the connexin 40 gene (GJA5) in atrial fibrillation. N Engl J Med 354: 2677-2688, 2006.

13. Xia M, Jin Q, Bendahhou S, He Y, Larroque MM, Chen Y, Zhou Q, Yang Y, Liu Y, Liu B, et al: A Kir2.1 gain-of-function mutation underlies familial atrial fibrillation. Biochem Biophys Res Commun 332: 1012-1019, 2005.

14. Yang Y, Li J, Lin X, Yang Y, Hong K, Wang L, Liu J, Li L, Yan D, Liang D, et al: Novel KCNA5 loss-of-function mutations responsible for atrial fibrillation. J Hum Genet 54: 277-283, 2009.

15. Christophersen IE, Olesen MS, Liang B, Andersen MN, Larsen AP, Nielsen JB, Hauns $\varnothing$ S, Olesen SP, Tveit A, Svendsen JH and Schmitt N: Genetic variation in KCNA5: Impact on the atrial-specific potassium current IKur in patients with lone atrial fibrillation. Eur Heart J 34: 1517-1525, 2013.

16. Wickenden AD: $\mathrm{K}(+)$ channels as therapeutic drug targets. Pharmacol Ther 94: 157-182, 2002.

17. Wulff H, Castle NA and Pardo LA: Voltage-gated potassium channels as therapeutic targets. Nat Rev Drug Discov 8: 982-1001, 2009.

18. King TJ and Bertram JS: Connexins as targets for cancer chemoprevention and chemotherapy. Biochim Biophys Acta 1719: 146-160, 2005.

19. Ravens U, Poulet C, Wettwer E and Knaut M: Atrial selectivity of antiarrhythmic drugs. J Physiol 591: 4087-4097, 2013.

20. Losa D, Chanson M and Crespin S: Connexins as therapeutic targets in lung disease. Expert Opin Ther Targets 15: 989-1002, 2011.

21. Bronis K, Metaxa S, Koulouris S and Manolis AS: Vernakalant: Review of a novel atrial selective antiarrhythmic agent and its place in current treatment of atrial fibrillation. Hosp Chron 7: 171-181, 2012.

22. Roy D, Pratt CM, Torp-Pedersen C, Wyse DG, Toft E, Juul-Moller S, Nielsen T, Rasmussen SL, Stiell IG, Coutu B, et al: Vernakalant hydrochloride for rapid conversion of atrial fibrillation: A phase 3, randomized, placebo-controlled trial. Circulation 117: 1518-1525, 2008.

23. Livak KJ and Schmittgen TD: Analysis of relative gene expression data using real-time quantitative PCR and the 2(-Delta Delta C(T)) method. Methods 25: 402-408, 2001.

24. Dries DL, Exner DV, Gersh BJ, Domanski MJ, Waclawiw MA and Stevenson LW: Atrial fibrillation is associated with an increased risk for mortality and heart failure progression in patients with asymptomatic and symptomatic left ventricular systolic dysfunction: a retrospective analysis of the SOLVD trials. Studies of left ventricular dysfunction. J Am Coll Cardiol 32: 695-703, 1998.

25. van der Velden HM, Ausma J, Rook MB, Hellemons AJ, van Veen TA, Allessie MA and Jongsma HJ: Gap junctional remodeling in relation to stabilization of atrial fibrillation in the goat. Cardiovasc Res 46: 476-486, 2000.

26. Ou XH, Li ML, Liu R, Fan XR, Mao L, Fan XH, Yang Y and Zeng XR: Remodeling of Kv1.5 channel in right atria from Han Chinese patients with atrial fibrillation. Med Sci Monit 21: 1207-1213, 2015.

27. Burstein B and Nattel S: Atrial fibrosis: Mechanisms and clinical relevance in atrial fibrillation. J Am Coll Cardiol 51: 802-809, 2008.

28. Casaclang-Verzosa G, Gersh BJ and Tsang TS: Structural and functional remodeling of the left atrium: Clinical and therapeutic implications for atrial fibrillation. J Am Coll Cardiol 51: 1-11,2008.

29. Zhang P, Su J and Mende U: Cross talk between cardiac myocytes and fibroblasts: From multiscale investigative approaches to mechanisms and functional consequences. Am J Physiol Heart Circ Physiol 303: H1385-H1396, 2012.

30. Söhl G and Willecke K: Gap junctions and the connexin protein family. Cardiovasc Res 62: 228-232, 2004.

31. Camelliti P, Borg TK and Kohl P: Structural and functional characterisation of cardiac fibroblasts. Cardiovasc Res 65: 40-51, 2005.

32. Carnes CA, Chung MK, Nakayama T, Nakayama H, Baliga RS, Piao S, Kanderian A, Pavia S, Hamlin RL, McCarthy PM, et al: Ascorbate attenuates atrial pacing-induced peroxynitrite formation and electrical remodeling and decreases the incidence of postoperative atrial fibrillation. Circ Res 89: e32-e38, 2001. 
33. Pongs O: Voltage-gated potassium channels: From hyperexcitability to excitement. FEBS Lett 452: 31-35, 1999.

34. Everett TH, Li H, Mangrum JM, McRury ID, Mitchell MA, Redick JA and Haines DE: Electrical, morphological, and ultrastructural remodeling and reverse remodeling in a canine model of chronic atrial fibrillation. Circulation 102: 1454-1460, 2000.

35. Benjamin EJ, Wolf PA, D'Agostino RB, Silbershatz H, Kannel WB and Levy D: Impact of atrial fibrillation on the risk of death the Framingham heart study. Circulation 98: 946-952, 1998.
36. Allessie MA, Boyden PA, Camm AJ, Kléber AG, Lab MJ, Legato MJ, Rosen MR, Schwartz PJ, Spooner PM, Van Wagoner DR and Waldo AL: Pathophysiology and prevention of atrial fibrillation. Circulation 103: 769-777, 2001.

37. Morillo CA, Klein GJ, Jones DL and Guiraudon CM: Chronic rapid atrial pacing. Structural, functional, and electrophysiological characteristics of a new model of sustained atrial fibrillation. Circulation 91: 1588-1595, 1995. 